\title{
El derecho al trabajo: en tránsito del despido libre al derecho constitucional garantizado
}

\author{
The right to work: transition from free dismissal \\ to guaranteed constitutional right
}

\author{
ALFREDO VILLAVICENCIO RÍOS*
}

Resumen: Tras presentar la evolución del derecho de estabilidad laboral en el Perú, se precisan los alcances públicos y privados del derecho al trabajo, que permitieron al Tribunal Constitucional redefinir el régimen del despido (estabilidad laboral de salida), en general, y comenzar a precisar el régimen de contratación temporal (estabilidad laboral de entrada). Se analiza la redefinición del marco jurídico del despido a partir de la jurisprudencia constitucional y judicial, poniendo en relieve los temas resueltos y los pendientes.

Palabras clave: despido libre - derecho al trabajo - estabilidad laboral de entrada y de salida - principio de causalidad en la contratación - proceso de constitucionalización - contratación temporal e indefinida

Summary: After presenting the evolution of labor stability law in Peru, public and private scopes of the right to work are described allowing the Constitutional Court redefine dismissal regime (working stability of exit), in general, and specifying temporary recruitment regime (working stability of entry). Redefinition of dismissal legal framework is analyzed from constitutional and judicial case law stressing solved and pending issues.

Key words: free dismissal - right to work - labor stability of entry and exit principle of causality concerning recruitment - constitutionalization process temporal and indefinite recruitment

CONTENIDO: I. BREVE EVOLUCIÓN HISTÓRICA DE LA PROTECCIÓN DEL DERECHO AL TRABAJO: EL PÉNDULO ENTRE EL DESPIDO LIBRE Y LA ESTABILIDAD LABORAL.- II. EL DERECHO AL TRABAJO: REGULACIÓN Y CONTENIDO. II.1. ALCANCES CONSTITUCIONALES Y FACETAS PÚBLICA Y PRIVADA DEL DERECHO AL TRABAJO. II.2. EL DERECHO DE ESTABILIDAD LABORAL Y SUS DOS EXPRESIONES (ÍNTIMAMENTE VINCULADAS).III. LA CONSTITUCIONALIZACIÓN DEL DERECHO AL TRABAJO.- IV. LA RECONSTRUCCIÓN DEL ORDENAMIENTO LABORAL: EL RETORNO PAULATINO A LA VIGENCIA TODAVÍA PARCIAL DEL DERECHO AL TRABAJO. IV.1. ALCANCES DE LA REDEFINICIÓN JURISDICCIONAL DE LA ESTABILIDAD DE ENTRADA.

* Doctor en Derecho por la Universidad de Sevilla. Director del Programa de Doctorado, de la Maestría en Relaciones Labores y profesor principal de la Pontificia Universidad Católica del Perú. Correo electrónico: alfredo.villavicencio@ @ucp.pe 


\section{IV.2. ALCANCES DE LA REDEFINICIÓN JURISDICCIONAL DE LA ESTABILIDAD}

DE SALIDA.- V. CONCLUSIONES FINALES.

La contratación laboral se caracteriza porque en ella, junto con una amplia libertad de contratar, convive una libertad de contractual restringida, en la medida en que el contenido del contrato de trabajo está fuertemente condicionado por la ley y el convenio colectivo. En este reparto de espacios legales, convencionales y contractuales que definen el estatus jurídico de un trabajador, hay temas que no pueden dejarse en el terreno del acuerdo de voluntades individual o colectivo, ya que están referidos al campo de los derechos fundamentales del trabajador y, en consecuencia, se regulan al más alto nivel y tienen que ser respetados necesariamente por la comunidad.

Este es el caso del derecho al trabajo, recogido en la Constitución peruana y en diversos pactos internacionales de derechos humanos, que además tiene una singular importancia, puesto que en sus diversas facetas es la base sobre la cual se construye gran parte de la efectividad de la regulación laboral y, como ha sostenido Sanguineti, «la garantía de este derecho guarda una estrecha conexión con la tutela de la dignidad de la persona y el ejercicio de los atributos propios de la ciudadanía» ${ }^{1}$. Y en ese marco, tenemos que partir señalando que estamos ante un derecho esencialísimo, que trasciende el ya importante contenido propio de causalidad en la contratación y en la extinción del contrato de trabajo, para erigirse en la piedra de toque sobre la que se construye gran parte de la eficacia del ordenamiento jurídico laboral y sus posibilidades de mejora.

La precisión de su contenido ha merecido quizás la más relevante jurisprudencia del Tribunal Constitucional en materia laboral y en lo que va del siglo XXI, razón por la cual decidimos abordar este proceso en las páginas que siguen.

I. BREVE EVOLUCIÓN HISTÓRICA DE LA PROTECCIÓN DEL DERECHO AL TRABAJO: EL PÉNDULO ENTRE EL DESPIDO LIBRE Y LA ESTABILIDAD LABORAL

La legislación peruana recogió durante varios años un modelo de estabilidad absoluta en los términos descritos en el capítulo anterior, que llegó a su cenit con su consagración en la Constitución de 1979. Empero, durante la década de 1990 presenciamos una transición hacia un modelo de mínima protección contra el despido arbitrario que se vio consolidada con la Constitución de 1993 y la posterior Ley de Productividad de

1 Véase http://www.wilfredosanguineti.es/El derecho al trabajo y la protección frente al despido en el derecho internacional. 
Competitividad Laboral, norma que nos rige en la actualidad y que consagra el despido libre indemnizado. Esta última situación se ha visto radicalmente reformulada por la actuación jurisdiccional del Tribunal Constitucional, como veremos en el capítulo III de este trabajo.

La ley 4916 (de 1924) es la primera norma laboral que se ocupa de la protección frente al despido, estableciendo una indemnización en casos de cesación de empleo, modificando el artículo 296 del entonces Código de Comercio. Luego de casi cincuenta años de vigencia, en 1970 se promulgó el decreto ley 18471, que estableció un régimen de estabilidad laboral absoluta para los trabajadores, pues solo permitía el despido en casos de reducción o despedida total de personal, autorizada por resolución de la autoridad de trabajo debido a causa económica o técnica y caso fortuito o fuerza mayor, o, una vez superado el período de prueba, por falta grave, que debía ser probada por el empleador. En caso contrario, el trabajador se encontraba facultado: (i) a la reposición en el trabajo y el pago de una suma igual a las remuneraciones que hubiere dejado de percibir hasta el momento de la reposición, así como a los otros derechos que pudieren corresponder, o (ii) al pago del equivalente de tres meses de remuneración, si el trabajador se decidiese por la terminación de la relación de trabajo, además de una suma igual a las remuneraciones dejadas de percibir hasta la fecha de resolución que pone término a la reclamación y demás derechos que pudieran corresponderle.

En 1978 se promulgó el decreto ley 22126, con el objetivo expreso de ser una norma que posibilitara la correcta interpretación y aplicación del decreto ley 18471. De este modo, el artículo 3 del decreto ley 22126 reafirmó la estabilidad laboral como regla en el ordenamiento jurídico; empero, en supuestos de trabajadores que no superaran los tres años al servicio de su empleado, podían ser despedidos sin causa justificada, con un preaviso de noventa días calendario y con una indemnización especial equivalente a noventa días de remuneración (artículo 28). En caso que la causal de despido no hubiese sido probada por el empleador, el trabajador mantenía la opción de: (i) solicitar su reposición con un pago de hasta seis meses de remuneraciones que se hubieren devengado a la Autoridad de Trabajo, o (ii) dar por terminada la relación laboral y solicitar una indemnización especial equivalente a doce remuneraciones mensuales, solicitud que debía presentarse ante el Fuero Privativo del Trabajo (Poder Judicial). Dicha disposición no se aplicaba a los dirigentes sindicales.

Un año después de la entrada en vigencia del decreto ley 22126 se aprobaba la Constitución de 1979, que entró en vigencia el 28 de julio de 1980, y en cuyo artículo 48 se establecía un régimen de estabilidad absoluta muy claro y preciso, al disponer que «el Estado reconoce el derecho de estabilidad en el trabajo. El trabajador solo puede ser 
despedido por causa justa, señalada en la ley debidamente comprobada». En ese nuevo marco constitucional, y a la luz de las disposiciones del Convenio 158 de la Organización Internacional del Trabajo (OIT), que no estaba (ni está) ratificado por el Perú, pero cuya influencia es muy clara también, en 1986 se promulgó la ley 24514, eliminando el período de «adquisición» de tres años del derecho de estabilidad laboral ${ }^{2}$ y retornando al esquema de estabilidad laboral absoluta. Como acota Blancas ${ }^{3}$, padre de la nueva regulación que impulsó desde su puesto de ministro de Trabajo, a diferencia de la norma anterior se procedió a enumerar las causas justas de despido, plasmando una concepción o sentido amplio de este: comenzaron a considerarse como falta grave las situaciones excepcionales de la empresa, como causas económicas, técnicas, caso fortuito y fuerza mayor, para seguir con las derivadas de la conducta del trabajador. Del mismo modo, la norma introdujo un procedimiento previo al despido para que el trabajador pudiera defenderse de las imputaciones del empleador, que se llevaba a cabo en el ámbito de la empresa. Asimismo, la ley unificó las acciones contra el despido, estableciendo como única sede la judicial; además, comprendió por primera vez en el derecho de estabilidad laboral a los trabajadores de confianza, entre otros aspectos.

Luego de cinco años de vigencia, el Poder Ejecutivo emitió el decreto legislativo 728, norma que significó, en líneas generales, «el inicio de la transición desde el modelo de estabilidad laboral absoluta hacia un modelo de mínima protección ante el despido, finalmente plasmada en la Constitución de 1993 y las leyes posteriormente dictadas al amparo de esta» ${ }^{4}$. Para ello, delimitó la noción de «despido» que tenían las leyes anteriores, reconduciéndola al despido individual relacionado con la capacidad o conducta del trabajador, excluyendo el cese del personal por razones objetivas. Además, a la figura del «despido injustificado» añadió la figura del «despido nulo». Este consistía en un despido que vulneraba derechos o valores fundamentales de especial importancia para el ordenamiento, como la libertad sindical, la igualdad, la maternidad, entre otros.

Sin embargo, si bien el despido nulo mantenía el remedio de la reposición del trabajador (artículo $71^{5}$ ), no sucedía lo mismo en el

2 «Artículo 2.- Están amparados por la presente ley los trabajadores sujetos al régimen de la actividad privada o de las empresas públicas sometidas al régimen laboral de la actividad privada, que laboren cuatro o más horas diarias para un mismo empleador, cualquiera que fuera la naturaleza del patrimonio de este o la modalidad empresarial que adopte, y siempre que hayan superado el período de prueba de tres meses.

3 Blancas Bustamante, Carlos. El despido en el derecho laboral peruano. Lima: ARA, 2006, pp. 105-106.

4 lbíd., p. 106.

5 «Artículo 71.- En los casos de nulidad de despido del artículo 65 el trabajador podrá demandar que se declare dicha nulidad y se proceda a su reposición en el empleo. En estos casos si el despido es declarado nulo el trabajador será repuesto en su empleo». 
despido injustificado: en el caso del despido arbitrario, el trabajador podía demandar alternativamente que sea repuesto o el pago de una indemnización, con la salvedad de que el juez estaba autorizado a ordenar el pago de una reparación en lugar de la reposición solicitada por el trabajador cuando esta última resultare inconveniente dadas las circunstancias (artículo 72). Ello significaba que el trabajador podía ganar el juicio contra el despido, pero de todas formas perdía su empleo, prevaleciendo lo dispuesto por el empleador, lo que implicaba desconocer la estabilidad laboral reconocida en la Constitución de $1979^{6}$. Cabe recordar para tal caso que la Ley Autoritativa 25327 permitió al Poder Ejecutivo legislar sobre la "promoción del acceso masivo al trabajo», condicionando tal autorización al respeto a las «normas constitucionales de estabilidad laboral y los derechos adquiridos de los trabajadores» (artículo 1), requisito que no fue cumplido por el gobierno fujimorista.

El decreto legislativo 728 introdujo, además, nuevas causales de despido relacionadas con la capacidad del trabajador. Asimismo, se permitió la ampliación del período de prueba, por mutuo acuerdo, hasta por un año; de este modo, el derecho a la estabilidad absoluta era muchas veces postergado, tomando en cuenta el casi nulo poder negociador del trabajador. Además, se ampliaron las causales objetivas para el cese colectivo de trabajadores, añadiendo la disolución y liquidación de la empresa, así como la quiebra de esta y sus necesidades de funcionamiento. Finalmente, acogió diversos contratos sujetos a modalidad, como el contrato por inicio o lanzamiento de nueva actividad, por necesidades de mercado y por reconversión empresarial; el contrato ocasional, de suplencia y de emergencia, y el contrato específico, intermitente y de temporada (artículos 97, 98 y 99 del decreto legislativo), que aumentaban el abanico de posibilidad del empleador para contratar temporalmente a sus trabajadores, en general, y especialmente le permitían, en el caso del contrato por inicio o incremento de actividades, contratar a plazo fijo para labores permanentes, quebrando el principio de causalidad en la contratación laboral.

Tras el golpe de Estado de Fujimori se tuvo que convocar al Congreso Constituyente, que aprobó en 1993 una nueva Constitución, de corte muy liberal y, por lo mismo, con una lacónica consagración de derechos sociales, que se desarrollan con más detalle en el capítulo siguiente. Baste señalar que su artículo 27 dispone «la ley otorga al trabajador adecuada protección contra el despido arbitrario». Con ello, se legitimó el régimen de despido libre indemnizado que comenzó a implementarse con el decreto legislativo 728 y que se perfeccionaría con la ley 26513 de julio de 1995. A continuación, este decreto legislativo se subdividiría en dos, por disposición del decreto legislativo 855: la Ley de Formación 
y Promoción Laboral (D.S. 002-97-TR) y la Ley de Productividad y Competitividad Laboral (D.S. 003-97-TR).

La nueva Ley de Productividad y Competitividad Laboral estableció en su artículo 34:

[...] Si el despido es arbitrario por no haberse expresado causa o no poderse demostrar esta en juicio, el trabajador tiene derecho al pago de la indemnización establecida en el artículo 38, como única reparación por el daño sufrido. Podrá demandar simultáneamente el pago de cualquier otro derecho o beneficio social pendiente $[\ldots]$.

Tal artículo constituyó el apogeo de la nueva regulación neoliberal de las relaciones laborales en el país, permitiendo el despido incausado en dos supuestos, englobados erróneamente bajo el concepto de «despido arbitrario»: (i) el despido con señalamiento de causa que no se demuestra en juicio, y (ii) el despido sin señalamiento de causa, siendo este último el despido ad nutum propiamente dicho, que atenta flagrantemente contra el derecho al trabajo y la estabilidad laboral. La consagración legal del despido libre incausado, sin embargo, no era acorde ni siquiera con el mismo articulado de la ley, pues esta, en su artículo 22, solicitaba causa justa contemplada en la ley y debidamente comprobada para la procedencia del despido del trabajador.

Finalmente, con relación a la contratación a plazo fijo, presenciamos el tránsito de un régimen donde la excepción eran los contratos temporales (artículo 37 del decreto legislativo $728^{7}$ ) a un modelo donde se permitía la libre contratación temporal (artículo 4 de la Ley de Productividad y Competitividad Laboral ${ }^{8}$ ), en detrimento de la estabilidad de entrada.

\section{EL DERECHO AL TRABAJO: REGULACIÓN Y CONTENIDO \\ II.1. Alcances constitucionales y facetas pública y privada del derecho al trabajo}

La Constitución de 1993 otorga la máxima consideración posible al trabajo cuando establece en su artículo 22 que «el trabajo es un deber y un derecho. Es base del bienestar social y un medio de realización de la persona». A lo que hay que añadir lo previsto en su artículo 23 que, bajo el rubro El Estado y el Trabajo, señala que:

7 «Artículo 37.- [...] Por excepción, pueden celebrarse por escrito contratos para obra o servicios determinados o sometidos a condición o sujetos a plazo en los casos y con los requisitos que la presente Ley establece [...]».

8 «Artículo 4.- [...] El contrato individual de trabajo puede celebrarse libremente por tiempo indeterminado o sujeto a modalidad. El primero podrá celebrarse en forma verbal o escrita y el segundo en los casos y con los requisitos que la presente ley establece». 
El trabajo, en sus diversas modalidades, es objeto de atención prioritaria del Estado, el cual protege especialmente a la madre, al menor de edad y al impedido que trabajan. El Estado promueve condiciones para el progreso social y económico, en especial mediante políticas de fomento del empleo productivo y de educación para el trabajo. Ninguna relación laboral puede limitar el ejercicio de los derechos constitucionales, ni desconocer o rebajar la dignidad del trabajador [...].

De esta regulación salta a la vista que, si bien no estamos ante un texto tan intenso en la relación Estado-trabajo como el de la Constitución de 1979 (donde se definía en el artículo 79 al Perú como «una República democrática y social, independiente y soberana, basada en el trabajo» $)^{9}$, hay una consideración jurídica superlativa del trabajo tanto en el ámbito social («base del bienestar social») como individual («mediode realización de la persona»), definiendo, además, los roles estatales generales de atención prioritaria, promoción y fomento, dejando absolutamente claro que en las relaciones laborales queda proscrita cualquier afectación de los derechos constitucionales (vengan de donde vengan) o cualquier otra condición o situación que pueda desconocer o rebajar la dignidad del trabajador. A este marco habría que agregar el mandato al Estado de proteger adecuadamente a cualquier trabajador en el terreno de la extinción de su relación laboral, previsto en el artículo 27, que dispone que «la ley otorga al trabajador adecuada protección contra el despido arbitrario».

Habida cuenta que en nuestro ordenamiento jurídico constitucional se ha previsto la figura del bloque de constitucionalidad ${ }^{10}$, habría que traer a colación el Pacto Internacional de Derechos Económicos, Sociales y Culturales de la Organización de las Naciones Unidas (ONU), adoptado en 1966, en cuyo artículo 6.1 se reconoce y garantiza «el derecho a trabajar, que comprende el derecho de toda persona a tener la oportunidad de ganarse la vida mediante un trabajo libremente escogido o aceptado», además de reconocer en su artículo 7.c el derecho a la igualdad de oportunidades al momento de la promoción dentro del trabajo, «sin más consideraciones que los factores de tiempo de servicio y capacidad».

Del mismo modo, el Protocolo Adicional a la Convención Americana sobre Derechos Humanos en Materia de Derechos Económicos, Sociales y Culturales — «Protocolo de San Salvador»— señala que toda persona tiene derecho al trabajo, el cual incluye la oportunidad de obtener los

9 El referente más importante de la corriente de países que otorgan al trabajo un rol superlativo es la Constitución italiana vigente, cuyo artículo 1 establece que «Italia es una República democrática fundada en el trabajo".

10 Véase, sobre el particular, VILLAVICENCIO Ríos, Alfredo. «Los tratados sobre derechos humanos y sus interpretaciones como parte del bloque de constitucionalidad». En VV.AA. Temas centrales del derecho del trabajo en el siglo XXI. Lima: ARA, 2009. 
medios para llevar una vida digna y decorosa a través del desempeño de una actividad lícita libremente escogida o aceptada (artículo 6.1). También garantiza este instrumento normativo el derecho del trabajador a la promoción o ascenso dentro de su trabajo teniendo en cuenta sus calificaciones, competencia, probidad y tiempo de servicio (artículo 7.c) y la estabilidad en el empleo, por lo que, en caso de despido injustificado, el trabajador tendrá derecho a una indemnización o a la readmisión en el empleo o a cualesquiera otra prevista por la legislación nacional (artículo 7.d).

Finalmente, el Convenio 158 de la OIT dispone en su artículo 4 que no se podrá terminar la relación de trabajo de un trabajador, a menos que exista para ello una causa justificada relacionada con su capacidad o su conducta o basada en las necesidades de funcionamiento de la empresa, establecimiento o servicio. Asimismo, el artículo 5 prohíbe los siguientes motivos como causa justificada para la terminación de la relación laboral: la afiliación a un sindicato o participación en actividades sindicales, ser candidato a representante de los trabajadores o haber actuado en esa calidad, presentar una queja contra el empleador o participar en procedimientos contra este, la ausencia del trabajo durante la licencia de maternidad y la raza, el color, el sexo, el estado civil, las responsabilidades familiares, el embarazo, la religión, las opiniones políticas, la ascendencia nacional o el origen social. Si bien este convenio lamentablemente no ha sido ratificado por nuestro país, mantiene la condición de recomendación, por lo que debe tomado en consideración por el ordenamiento.

Teniendo como marco la normativa constitucional reseñada, debemos señalar que el derecho al trabajo se manifiesta en dos facetas: pública y privada. La primera gira alrededor de las obligaciones estatales de definición e implementación de políticas públicas dirigidas a favorecer el acceso de los ciudadanos a un empleo, en tanto que la segunda gira alrededor del derecho a conservar un empleo determinado, salvo que se incurra en una causa justa de extinción. Veamos a continuación los linderos de estas facetas.

En la faceta pública, el derecho al trabajo se inscribe en el marco de las políticas públicas que conduzcan al acceso a un puesto de trabajo genérico o específico ${ }^{11}$. En el primer caso, se trata de un elenco de políticas que generen un acceso progresivo y según las posibilidades del Estado ${ }^{12}$, razón por la cual no existe posibilidad de recurrir a un juzgado constitucional vía amparo. En el segundo caso, el derecho al trabajo se expresa específicamente en tanto estemos ante una

11 NeVES MuJICA, Javier. Derecho del trabajo. Cuestiones controversiales. Lima: ARA, 2010, p. 44. 12 STC 00824-2010-PA/TC, fundamento 4. 
postulación en un concurso público o interno, lo que conduce a que se acceda a un puesto de trabajo concreto ${ }^{13}$.

El sector público, para el caso de los concursos de acceso, o todo el sistema, para los casos de promociones internas, son los campos en donde se manifiesta esta faceta específica del derecho al trabajo (recordemos que el derecho a la promoción en el empleo se encuentra recogido en instrumentos internacionales ratificados por el Perú y que tienen rango constitucional: en el Pacto Internacional de Derechos Económicos, Sociales y Culturales ${ }^{14}$, y el Protocolo Adicional a la Convención Americana sobre Derechos Humanos en materia de Derechos Económicos, Sociales y Culturales ${ }^{15}$ ).

En la faceta privada, el derecho al trabajo alude a la conservación del empleo, salvo que se incurra en una causa justa que conduzca a privarlo válidamente de él ${ }^{16}$, postura que coincide con la del Tribunal Constitucional cuando afirma que el derecho al trabajo como conservación del empleo significa «el derecho a no ser despedido, sino por causa justa» ${ }^{17}$. La conservación del empleo, así entendida, coincide plenamente con el contenido que le atribuyen los juristas a la estabilidad de salida (prohibición del despido injustificado), una de las dos manifestaciones de la estabilidad laboral. Esta faceta sí abre la posibilidad a una tutela constitucional directa e inmediata a través del proceso de amparo, al punto que hay una nutrida jurisprudencia del Tribunal Constitucional al respecto, de la que nos iremos ocupando al hilo del desarrollo del tema medular en este terreno: la estabilidad laboral.

\section{II.2. El derecho de estabilidad laboral y sus dos expresiones (íntimamente vinculadas)}

La estabilidad es un derecho de vital importancia que ha merecido un amplísimo análisis académico. En esta ocasión,sin embargo, el objeto de estudio se centrará en el proceso deconstitucionalización vivido tras la última etapa legal, en la que se consagró un régimen de despido libre indemnizado. En función de ello, vamos a presentar de modo

13 NeVes MuJICA, Javier. Ob. cit., p. 45.

14 «Artículo 7.- Los Estados Partes en el presente Pacto reconocen el derecho de toda persona al goce de condiciones de trabajo equitativas y satisfactorias que le aseguren en especial:

c) Igual oportunidad para todos de ser promovidos, dentro de su trabajo, a la categoría superior que les corresponda, sin más consideraciones que los factores de tiempo de servicio y capacidad».

15 «Artículo 7.- Los Estados partes en el presente Protocolo reconocen que el derecho al trabajo al que se refiere el artículo anterior supone que toda persona goce del mismo en condiciones justas, equitativas y satisfactorias, para lo cual dichos Estados garantizarán en sus legislaciones nacionales, de manera particular:

c. el derecho del trabajador a la promoción o ascenso dentro de su trabajo para lo cual se tendrán en cuentas sus calificaciones, competencia, probidad y tiempo de servicio".

16 Blancas Bustamante, Carlos. Ob. cit., p. 73.

17 STC 1124-2001-PA/TC, fundamento 12.

\section{EL DERECHO AL TRABAJO: EN TRÁNSITO DEL DESPIDO LIBRE AL DERECHO CONSTITUCIONAL GARANTIZADO}

\section{THE RIGHTTO}

WORK:TRANSITION FROM FREE DISMISSALTO GUARANTEED CONSTITUTIONAL RIGHT 
muy sucinto sus principales alcances y expresiones, para dejar sentado el marco de referencia doctrinal y legal sobre el que se ha movido la jurisprudencia constitucional que lo ha redefinido.

La estabilidad laboral posee dos expresiones: la estabilidad de entrada y la de salida, que a pesar de que se encuentran al comienzo y al final de la relación laboral tienen un grado de comunicación muy intenso, como se verá próximamente.

La estabilidad laboral de entrada se centra en el momento inicial de la relación laboral y vincula la duración del contrato con la naturaleza de las labores. En tal sentido, implica una relación causal entre la naturaleza permanente o temporal de las labores para las que se contrata con la duración indefinida o a plazo fijo del contrato que se debe suscribir para llevarlas a cabo. En función de ello, Pasco Cosmópolis ha afirmado que la autorización para la contratación temporal debe darse solo en casos en que se cubran labores de tal naturaleza, pues el contrato de trabajo posee vocación de permanencia, siendo su duración proporcional a la causa que lo motivó ${ }^{18}$.

Por tanto, la duración del contrato es una materia que escapa a la libertad de contratación de las partes, en la medida en que su trascendencia la ha llevado al ámbito de la regulación legal, que si bien utiliza una variada tipología contractual, porque la naturaleza de las labores temporales así lo requiere, por regla general no puede sustraerse al principio de causalidad enunciado inicialmente. En consecuencia, si se transgreden las reglas de contratación temporal o se continúa prestando servicios una vez concluido el contrato temporal, el ordenamiento jurídico entiende que se ha producido una desnaturalización de la contratación temporal y dispone que la relación laboral pase a ser de duración indefinida (artículo 77 de la Ley de Productividad y Competitividad Laboral, en adelante LPCL).

Además del principio de causalidad, el ordenamiento laboral peruano tiene una clara preferencia por la contratación indefinida, recogida a través de una presunción establecida en el artículo 4 de la LPCL, que establece que toda prestación personal y subordinada se considerará $a b$ initio indefinida, salvo que se demuestre su temporalidad. Finalmente, en nuestro país se sigue considerando a la contratación indefinida como la típica, la ordinaria, razón por la cual no se le exige formalidad alguna, en tanto que si uno requiere utilizar una modalidad temporal, tiene necesariamente que celebrarla por escrito y que en este contrato se consignen expresamente las causales de 
contratación (artículo 72 de la LPCL), y los transforma en contratos indefinidos en caso exista simulación o fraude a la ley o los trabajadores continúen laborando luego de vencido el contrato (artículo 77 de la LPCL).

La estabilidad laboral de salida, que se ubica en el momento final de la relación laboral, implica la permanencia del vínculo laboral salvo que se produzca una causa justa que permita terminarlo, de allí que tenga como consecuencia la prohibición del despido arbitrario o injustificado, como exige nuestro Tribunal Constitucional ${ }^{19}$. De esta forma, la potestad del empleador para finalizar la relación laboral se limita y pasa a considerarse un poder excepcional.

Para hacer efectivo este derecho, los distintos ordenamientos jurídicos han planteado diversos remedios ante su vulneración. En la doctrina y la jurisprudencia se maneja una clasificación general que la divide en absoluta y relativa, según su infracción conduzca a la reposición del trabajador injustamente despedido o solo al pago de una indemnización. Esta dualidad de remedios puede verse graficada en el artículo 7 del Protocolo de San Salvador, cuando afirma que «en casos de despido injustificado, el trabajador tendrá derecho a una indemnización o a la readmisión en el empleo o a cualesquiera otra prestación prevista por la legislación nacional». Debe agregarse que son muy comunes los modelos mixtos en los que se suele consagrar la estabilidad absoluta cuando la afectación lesiona derechos fundamentales, y la relativa cuando se trata de otros valores de menor jerarquía.

En todo caso, debe tenerse siempre presente que, al existir un derecho de estabilidad laboral derivado del derecho al trabajo, el despido ad nutum o sin causa tiene necesariamente como consecuencia la reposición del trabajador que lo cuestiona judicialmente, por lo que la protección relativa se predica residualmente para los casos en los que no esté en juego ninguno de los valores constitucionales o legales cuya afectación tiene prevista la reposición. Nuestro Tribunal Constitucional ha señalado que el pago de una compensación económica o indemnización por el accionar arbitrario del empleador constituye una «protección reparadora contra el despido arbitrario» y que está ligado a un sistema de protección de eficacia resarcitoria ${ }^{20}$. En el caso de la estabilidad absoluta, el Tribunal Constitucional ha señalado que estamos ante una «protección preventiva del despido arbitrario» ${ }^{21}$ que se vincula con una eficacia restitutoria respecto del despido. Se trata, en última instancia, de dejar sin efecto jurídico alguno al despido sin causa justa, reponiendo el estado de las cosas anterior a este hecho. 
La estabilidad laboral de entrada y la de salida tienen relaciones muy estrechas si las enfocamos desde la perspectiva integral del derecho al trabajo que conducen a cautelar ambas esferas para que el derecho sea efectivo. Dicho de otro modo, si protegemos una dimensión pero dejamos amplios márgenes de libertad en la otra, el derecho quedará a merced de conductas que lo hagan ineficaz. El ejemplo más claro de lo dicho se presenta cuando un régimen legal tiene una intensa protección contra el despido injustificado (estabilidad laboral absoluta), pero a la par no respeta el principio de causalidad en la contratación (ausencia de estabilidad laboral de entrada).

En este caso, que en buena medida es el peruano (puesto que se puede contratar a plazo fijo para labores permanentes utilizando el contrato de inicio o incremento de actividades, que da cuenta de la mitad de contratos temporales en el Perú), de poco sirve la protección contra el despido, puesto que la conclusión de labores opera por terminación del plazo del contrato y no por despido. Además de ello, basta con tener contratos temporales de corta duración para tener a los trabajadores en un régimen de gran fragilidad, puesto que cualquier actitud reivindicativa pondrá en juego la renovación del vínculo.

\section{LA CONSTITUCIONALIZACIÓN DEL DERECHO $A L T R A B A J O$}

La evolución legal que hemos reseñado párrafos atrás se da en un marco en el que se consideraba que las constituciones eran cuerpos político-jurídicos fundacionales pero con una eficacia jurídica muy relativa, razón por la cual la norma por excelencia era la ley y la forma política correspondiente se denominaba Estado legal de derecho. En los últimos veinte años, en América Latina ha cambiado este paradigma en los diversos países, de la mano de una concepción europea que comenzó a difundirse con fuerza en Alemania luego de la Segunda Guerra Mundial, por la cual la Constitución ha ido ocupando el lugar central de la arquitectura jurídica hasta definir el modelo como un Estado constitucional. En este modelo, la Constitución se convirtió en un instrumento «capaz de condicionar tanto la legislación como la jurisprudencia y el estilo doctrinal, la acción de los actores políticos, así como las relaciones sociales» ${ }^{22}$.

Si bien el constitucionalismo social se inicia con la promulgación de las constituciones de Querétaro (1917) y Weimar (1919), el proceso de prevalencia al que aludimos supuso ir dotando paulatinamente de una fuerza vinculante a las garantías recogidas por la Norma Suprema y de una función preservadora y protectora de derechos fundamentales, 
reconociéndose así una primacía de la Constitución sobre la legislación nacional ${ }^{23}$. En tal sentido, y como hace notar Landa ${ }^{24}$, ello sucedió debido a que el poder constituyente del que emana y el contenido esencial de la comunidad que expresa jurídicamente le confieren supremacía material, en tanto que sus características de lex legis (en tanto se encuentra en el vértice de las demás normas) y norma normarum (en tanto constituye norma matriz para la creación de las demás normas) le garantizan supremacía formal.

Dicho proceso significó concebir a la Constitución como la piedra angular de un proyecto político-social determinado, dentro del cual el conjunto de normas laborales debe ser visto de manera sistemática como uno de los ejes principales de la dimensión social del macroproyecto.

Este proceso de constitucionalización, sustentado en el súper valor de consagración y garantía de los derechos humanos, confluye con el desarrollo y la preocupación internacional por el mismo objetivo que vive el mundo desde que en 1948 se aprobó la Declaración Universal de Derechos Humanos y que ha dado numerosos frutos en el ámbito de los instrumentos internacionales sobre derechos humanos. Además de ello, la constitucionalización del derecho en el Perú vino aparejada con el concepto de «bloque de constitucionalidad», expresando que «las normas materialmente constitucionales - esto es, con fuerza constitucional — son más numerosas que aquellas que son formalmente constitucionales — esto es, aquellas que son expresamente mencionadas por el artículo constitucional— ${ }^{25}$. De este modo, por mandato de la propia Constitución (en nuestro caso, el artículo $3^{26}$ y la cuarta disposición final y transitoria ${ }^{27}$ ), las normas con este rango van más allá de su articulado y acogen disposiciones de origen diverso, como las internacionales, entre las que destacan especialmente los Pactos Internacionales de Derechos Humanos y los Convenios Internacionales de la OIT.

Asimismo, este proceso trajo consigo la consideración de que la Constitución no es una norma estática sino «en movimiento», que se adapta a los cambios que la sociedad experimenta, pese a responder

23 HESSE, Konrad. Derecho constitucional y derecho privado.Madrid: Civitas, 1995, pp. 48-49.

24 LANDA ARROYO, César. "La fuerza normativa constitucional de los derechos fundamentales». En Justicia constitucional y derechos fundamentales. Fuerza normativa de la Constitución. Uruguay: Fundación Konrad Adenauer, 2011, p. 25.

25 UPRIMI, Rodrigo. El bloque de constitucionalidad en Colombia: un análisis jurisprudencial y un ensayo doctrinal. En: www.dejusticia.org, 2004.

26 «Artículo 3.- La enumeración de los derechos establecidos en este capítulo no excluye los demás que la Constitución garantiza, ni otros de naturaleza análoga o que se fundan en la dignidad del hombre, o en los principios de soberanía del pueblo, del Estado democrático de derecho y de la forma republicana de gobierno".

27 «Cuarta. Las normas relativas a los derechos y a las libertades que la Constitución reconoce se interpretan de conformidad con la Declaración Universal de Derechos Humanos y con los tratados y acuerdos internacionales sobre las mismas materias ratificados por el Perú».

EL DERECHO AL TRABAJO: EN TRÁNSITO DEL DESPIDO LIBRE AL DERECHO CONSTITUCIONAL GARANTIZADO

THE RIGHTTO WORK:TRANSITION FROM FREE DISMISSALTO GUARANTEED CONSTITUTIONAL RIGHT 
al contexto en el que fue promulgada. Los órganos jurisdiccionales autorizados y sus interpretaciones vinculantes —para particulares y para el Estado- conllevan, así, la concepción dinámica de la Constitución. Estamos ante decisiones jurisdiccionales que, «al provenir de su intérprete auténtico, equivalen nada menos que a la Constitución misma ${ }^{28}$. En nuestro país, estas decisiones corresponden al Tribunal Constitucional, máximo intérprete de la Constitución por disposición deesta (artículo 205).

Entre las potestades que posee dicho Tribunal existe una que merece ser destacada: adecuar el ordenamiento infraconstitucional a los mandatos presentes en la Norma Suprema (control concentrado). Para ello, el Tribunal Constitucional se ha valido de tres herramientas que Sanguineti describe con precisión: la primera de ellas está referida a la interpretación de los preceptos constitucionales como porciones de un conjunto normativo más amplio informado por una lógica común, la segunda es el recurso a la «cláusula de apertura» prevista por la Cuarta Disposición Final y Transitoria de la Constitución (a la que nos permitimos agregar el artículo 3 del mismo cuerpo normativo), y la tercera está representada por una lectura de los preceptos de la Constitución acorde con el sistema de valores presente en ella ${ }^{29}$.

En el contexto señalado, el derecho al trabajo viene a ser un «derecho constitucionalmente condicionado», en la medida en que los preceptos constitucionales laborales son más explícitos y detallados, procurando brindar un marco general para su regulación por el legislador. Dado el significativo volumen de disposiciones constitucionales en materia constitucional, la labor de este se encuentra más condicionada en el derecho laboral que en el resto de áreas del derecho, consecuencia necesaria de la importancia del trabajo en la vida y en el ordenamiento constitucional.

Dentro de la gama de derechos laborales reconocidos en la Constitución, destacan justamente el derecho al trabajo y la estabilidad en el trabajo, que ya hemos tratado conceptualmente supra.

\section{LA RECONSTRUCCIÓN DEL ORDENAMIENTO LABORAL: EL RETORNO PAULATINO A LA VIGENCIA TODAVÍA PARCIAL DEL DERECHO AL TRABAJO}

Si bien la promulgación de la Constitución de 1993 involucró una reducción importante tanto en el volumen como en la tutela de los

28 SANGUINETI RAYMOND, Wilfredo. «Derecho constitucional del trabajo. Relaciones de trabajo en la jurisprudencia del Tribunal Constitucional».Gaceta Jurídica, Lima, 2007, p. 18. 29 Ídem, p. 43. 
derechos laborales en el ámbito constitucional, consideramos que no logró que el ordenamiento se aparte completamente de un modelo democrático y pluralista de relaciones laborale ${ }^{30}$.

En efecto, como ya se viera, la nueva Constitución también proclamó, como su antecesora, una especial valoración del trabajo. Así lo ha dado a entender en sus artículos 22 y 23 , donde afirma que «el trabajo es un deber y un derecho», «es base del bienestar social y un medio de realización de la persona», «en sus diversas modalidades, es objeto de atención prioritaria del Estado», «el Estado promueve condiciones para el progreso social y económico, en especial mediante políticas de fomento del empleo productivo y la educación para el trabajo».

Del mismo modo, la Constitución vigente, aunque en menor cantidad y desarrollo que la de 1979, consagró importantes principios y derechos laborales: en el primer caso encontramos la irrenunciabilidad de derechos, el indubio pro operario y la igualdad de oportunidades; en el segundo caso, el derecho al trabajo, el derecho a una remuneración equitativa y suficiente, el derecho a una jornada máxima, y el derecho a una protección adecuada contra el despido arbitrario, el derecho de sindicación, negociación colectiva y huelga, entre otros. Tales principios y derechos garantizan, aunque en menor medida, una cierta regulación estatal en aspectos clave de las relaciones individuales y colectivas de trabajo.

La razón de ello se debe a que «desconstitucionalizar» los derechos laborales del ordenamiento interno involucra dificultades no solo de carácter jurídico sino de carácter político, ya sea porque los derechos laborales forman parte de la definición básica del Estado social y democrático o porque la omisión del constituyente se puede suplir con lo regulado por normas internacionales (de ahí la importancia del «bloque de constitucionalidad»); además de ello, porque tales derechos contribuyen a la legitimación social de la Constitución ${ }^{31}$. Ante ese panorama, el constituyente de 1993 optó por garantizar un mínimo de derechos laborales, para otorgar así al legislador mayores cuotas de discrecionalidad en el tratamiento legal del derecho del trabajo, buscando justificar así la intensa flexibilidad que se había generado y que podía seguir acentuándose, como en efecto sucedió.

En el caso específico del derecho al trabajo, las consecuencias de dicha estrategia son conocidas. En primer término, en la década de 1990 se produjo una masificación de los despidos inmotivados o con causas falsas, obedeciendo muchas veces a una política de reducción

EL DERECHO AL TRABAJO: EN TRÁNSITO DEL DESPIDO LIBRE AL DERECHO CONSTITUCIONAL GARANTIZADO

\section{THE RIGHT TO}

WORK:TRANSITION FROM FREE DISMISSALTO GUARANTEED CONSTITUTIONAL RIGHT 
de personal o de afectación a la representación sindical en la empresa sin posibilidad de solicitar la reposición en el empleo, consecuencia del artículo 34 de la LPCL. Hay que recordar que su impacto en el campo sindical fue demoledor, como demuestran las cifras de cancelaciones de registros sindicales, que doblaron a las de inscripciones en los años 1995, 1996 y 1997, como se ve en el siguiente gráfico.

\section{Perú: registros sindicales en el sector privado 1993-2011}

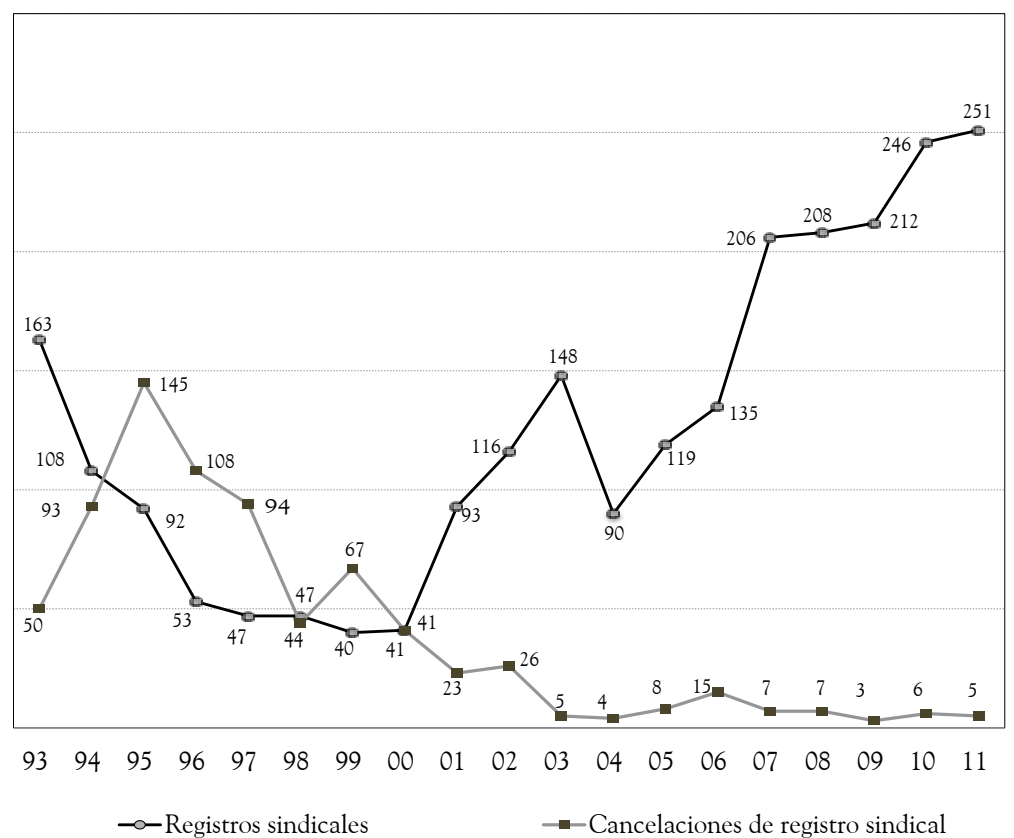

Fuente: Oficina de Estadística, MTPE. Elaboración propia.

Asimismo, la consagración en la mencionada ley de nueve tipos de contratos temporales con un plazo máximo de cinco años de duración, entre los que hay modalidades que implican la prestación de labores permanentes bajo contrato a plazo fijo (inicio o incremento de actividades), provocó que la contratación temporal se convierta en la principal forma de contratación en nuestro país - pese a que la regla debiera ser el vínculo indefinido-, como se puede apreciar en los siguientes gráficos ${ }^{32}$ :

32 Cabe indicar que, en el ámbito colectivo, la Ley de Relaciones Colectivas de Trabajo, por medio de una regulación reglamentarista, controlista y restrictiva del fenómeno sindical, a la par que profundizadora de un modelo descentralizado de relaciones de trabajo, terminó por casi desaparecer el movimiento sindical en nuestro país. Al respecto recomendamos revisar: VILLAVICENCIO Ríos, Alfredo. La libertad sindical..., Ob. cit., pp. 45-46. 
(1990 - 2008)

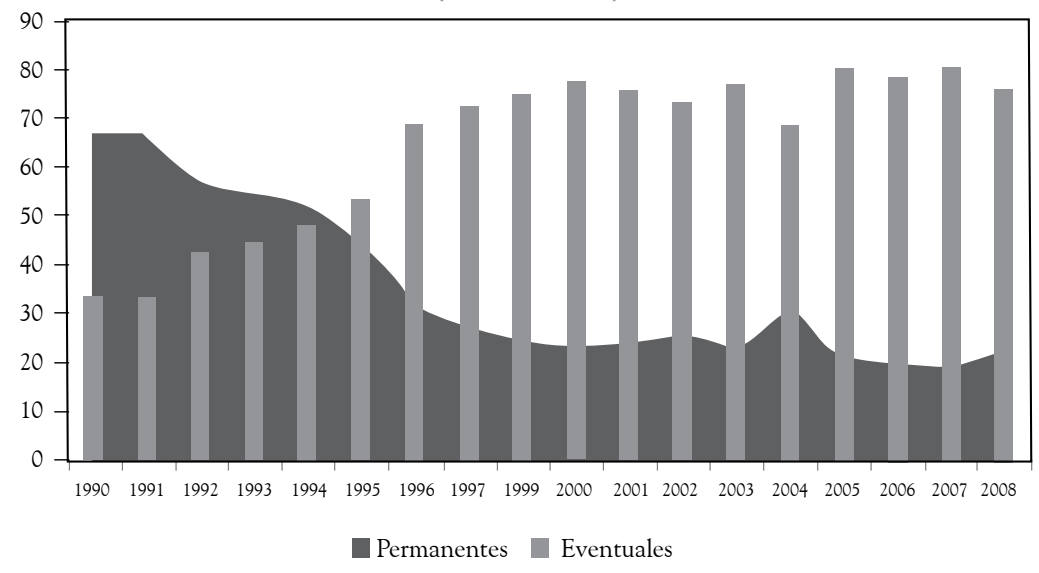

Fuente: De 1990 a 1997 en Olivera (1999). «Ampliación de la cobertura de pensiones: el caso de los trabajadores independientes en el Sistema Privado de Pensiones». Convenio MTPE-INEI, ENAHO 1999, 2000, 2001 III Trimestre. MTPE, Encuesta de hogares especializada en niveles de empleo, de 2002 a 2008 III Trimestre. Elaboración propia.

\section{Perú: Distribución de asalariados privados registrados en planilla según tipo de contrato 2005-2011}

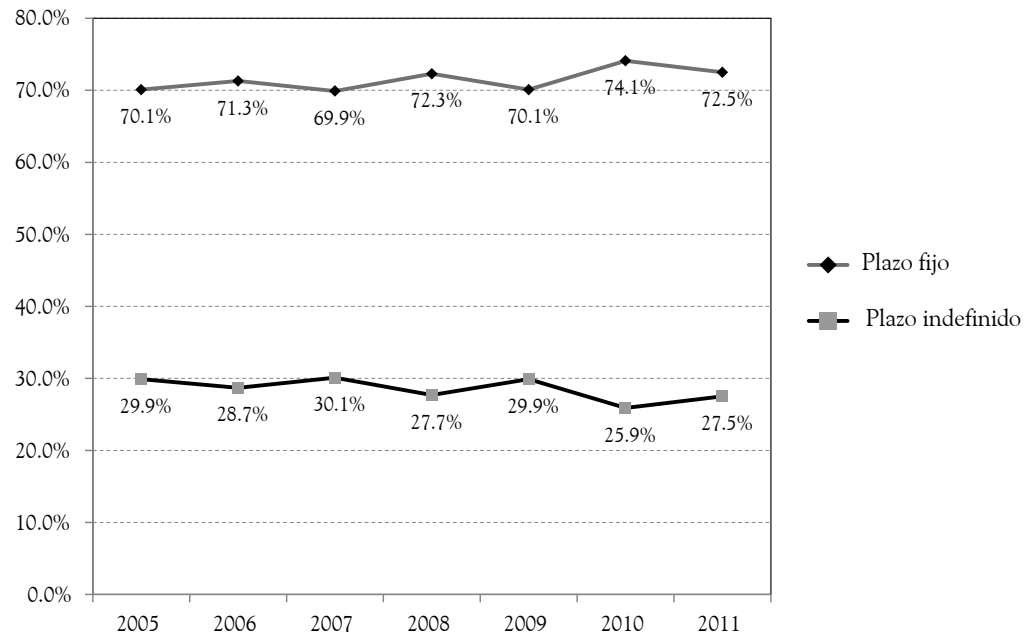

Fuente: ENAHO, INEI, MTPE. Elaboración propia.

Frente al contexto descrito, y ante la pasividad de los poderes del Estado $^{33}$, el Tribunal Constitucional desde la restauración democrática
EL DERECHO AL TRABAJO: EN

TRÁNSITO DEL DESPIDO LIBRE AL DERECHO CONSTITUCIONAL GARANTIZADO

\section{THE RIGHT TO}

WORK:TRANSITION FROM FREE DISMISSALTO GUARANTEED CONSTITUTIONAL RIGHT 
a finales del año 2000 ha asumido la importante responsabilidad de ir recomponiendo el sistema legal de derechos laborales a la luz de la norma suprema y los instrumentos internacionales suscritos por el Perú, haciendo uso de sus facultades de interpretación de la norma suprema y adecuación del ordenamiento infraconstitucional a los preceptos constitucionales. Esta actividad la ha llevado a cabo el Tribunal Constitucional a partir de la jurisprudencia en materia de procesos de amparo que pasamos a analizar a continuación.

\section{IV.1. Alcances de la redefinición jurisdiccional de la estabilidad de entrada}

Como ya hemos indicado, a diferencia de la Constitución de 1979, la Norma Suprema vigente no consagró expresamente el derecho a la estabilidad en el empleo, sea en sus variantes de entrada o de salida. No obstante, una lectura sistemática de los artículos 22 y 27 de la Constitución actual nos brinda elementos para entender comprendido dentro de dicho cuerpo normativo al principio de estabilidad en el empleo. En efecto, el derecho al trabajo recogido en el artículo 22 no solo comprende el derecho acceder a un puesto de trabajo en condiciones de igualdad, sino además implica conservar el puesto mientras no existan circunstancias que obsten a su continuidad, como ya hemos indicado anteriormente.

El Supremo Intérprete de la Constitución comenzó a transitar por este derrotero a partir de situaciones de fraude laboral en las que se suscribe un contrato temporal, pero las labores a las que se dedica el trabajador son permanentes. Este es el caso de la sentencia recaída en el expediente 1397-2001, entre Ángel De La Cruz Pomasoncco y otros contra EPSASA, en la que señaló que el régimen laboral peruano se basa en el principio de causalidad, en virtud del cual la duración del vínculo laboral debe ser garantizada mientras subsista la fuente que le dio origen, por lo que los contratos sujetos a modalidad deben poseer carácter excepcional (con formalidades y requisitos especiales) y proceder únicamente para cubrir labores temporales ${ }^{34}$. En tal sentido, un contrato temporal se considerará de duración indeterminada, en virtud del artículo 77 de la Ley de Productividad y Competitividad Laboral, si existió fraude o simulación a las normas laborales al momento de consignar la causa o naturaleza de los servicios.

Ante dicho supuesto, la respuesta del ordenamiento no solo debe ser la consideración del contrato temporal como uno indeterminado, sino además se debe tomar en cuenta que «cualquier determinación por parte del empleador para la culminación de la relación laboral 
solo puede sustentarse en una causa justa establecida por la ley, de lo contrario se trataría de un despido arbitrario, cuya proscripción garantiza el contenido esencial del derecho al trabajo, reconocido por el artículo 22 de la Constitución política vigente» ${ }^{35}$, invalidándose incluso las extinciones de contratos temporales por vencimiento de plazo en supuestos de desnaturalización. En estos casos, el Supremo Intérprete ha entendido que la ruptura del vínculo laboral, sustentada en una utilización fraudulenta de una modalidad de contratación, tiene el carácter de un despido absolutamente arbitrario - específicamente uno de carácter «incausado»-, frente al cual procede la reposición como expresión eminentemente restitutoria de todo proceso constitucional de tutela de derechos ${ }^{36}$.

Similar circunstancia acaeció en el expediente 01580-2008-PA/TC, donde el Tribunal determinó que los contratos temporales que recaen sobre labores permanentes debían considerarse como de duración indeterminada. Incluso para el caso de la obra o servicio específico, donde a simple vista el artículo 63 de la LPCL requeriría únicamente un objeto previamente establecido y una duración determinada en directa relación con la obra o servicio objeto de la contratación, la calificación de estos requisitos no puede hacerse al margen del ordenamiento constitucional. Por ello, en la sentencia recaída en el expediente 03771-2010-PA/TC, en un caso en el que se contrató bajo modalidad de obra o servicio determinado pero para realizar labores permanentes (llevar las planillas de una universidad), el Supremo Intérprete de la Constitución estableció:

Así, se entiende que esta modalidad contractual no puede ser empleada para labores de naturaleza permanente que podrían ser realizadas por un trabajador estable, sino que se trata más bien de una modalidad contractual que le permite al empleador dar cobertura a aquellas labores temporales o estrictamente especializadas que no forman parte de las labores permanentes de la empresa, y que requieran un plazo determinado, sustentado en razones objetivas, que puede ser renovado en la medida en que las circunstancias así lo ameriten. Lo contrario, es decir, permitir que esta modalidad de contratación «por obra determinada» o «servicio específico» sea usada para la contratación de trabajadores que van a realizar labores permanentes o del giro principal de la empresa, vulneraría el contenido del derecho al trabajo en su segunda acepción ${ }^{37}$.

De este modo, el Tribunal ha dejado de lado el remedio de la indemnización por despido arbitrario del artículo 34 de la LPCL ante

EL DERECHO AL TRABAJO: EN TRÁNSITO DEL DESPIDO LIBRE AL DERECHO CONSTITUCIONAL GARANTIZADO

THE RIGHTTO WORK:TRANSITION FROM FREE DISMISSALTO GUARANTEED CONSTITUTIONAL RIGHT 
estos supuestos de vulneración del derecho al trabajo, ordenando la readmisión del empleo en el marco de situaciones donde, de acuerdo con el Tribunal, se han dado despidos sin causa ${ }^{38}$.

Visto lo anterior, tenemos que señalar que la actuación del Tribunal se ha limitado a pronunciarse en los casos de fraude en la contratación temporal (utilización de modalidades temporales para encubrir prestaciones en actividades permanentes), sin entrar a analizar si la propia modalidad contractual prevista por la ley recaía sobre labores permanentes y, por lo tanto, dicha modalidad debería ser expulsada del ordenamiento por infringir el principio de causalidad. Tal es el caso del decreto ley 22342, que permite a las empresas de exportación no tradicional contratar para labores permanentes a personal eventual en el número que requieran, con posibilidad de renovar indefinidamente los contratos temporales, sin siquiera el límite de cinco años que establece la LPCL para la contratación a plazo fijo. Al respecto, el Colegiado indicó en la sentencia recaída en el expediente 04409-2011-PA/TC que «la sola suscripción de un contrato de trabajo sujeto a modalidad bajo el régimen laboral especial del decreto ley 22342 no puede ser considerada como un supuesto de desnaturalización, salvo que se demuestre que la empleadora no es una empresa industrial de exportación no tradicional» ${ }^{39}$, revocando el pronunciamiento de primera instancia que había determinado la desnaturalización de los contratos de exportación no tradicional en vista de que la demandante había sido contratada para realizar labores permanentes. Tampoco se ha pronunciado sobre el contrato para inicio o incremento de actividades que autoriza la contratación temporal para labores permanentes y que es el gran responsable de la distorsión de nuestras relaciones laborales, en las que, como ya se viera, tres de cada cuatro contratos son temporales (y de los tres temporales la mitad lo son a través del contrato referido).

En tal sentido, consideramos que el Supremo Intérprete de la Constitución, además de pronunciarse contra el fraude en la contratación temporal, debería examinar los contratos a plazo fijo que se aplican a relaciones de trabajo de carácter permanente, y que, por lo mismo, implican una vulneración a la estabilidad de entrada y por ende al principio de causalidad que el Tribunal ha defendido en la sentencia recaída en el expediente 01397-2001-PA/TC. La tutela procesal hacia estos trabajadores es urgente, pues la afectación a la estabilidad laboral implica, además, que en la práctica no puedan gozar de otros derechos

38 El Colegiado ha aplicado de forma reiterada este criterio principalmente en situaciones donde el trabajador continua laborando después de culminado el contrato sujeto a modalidad y por desnaturalización de las modalidades de contratación temporal admitidas por la ley. Al respecto, revisar las sentencias 03012-2004-PA/TC y 04168-2005-PA/TC.

39 Fundamento 3. 
fundamentales, comenzando por los colectivos que son la base de la tutela laboral.

\section{IV.2. Alcances de la redefinición jurisdiccional de la esta- bilidad de salida}

Si bien existen sentencias aisladas que reafirman la vigencia del derecho constitucional al trabajo sobre la legislación de la década de 1990, es a partir del fin de la década de 2000 que el Tribunal Constitucional emite tres pronunciamientos sustancial es que, a la fecha, continúan vinculando a la jurisprudencia de ese Colegiado y que plantean: la inconstitucionalidad del artículo 34 de la LPCL por vaciar de contenido el derecho al trabajo, la extensión de la garantía de readmisión en el empleo a supuestos distintos al despido nulo (bajo una nueva categorización del despido) y la tutela procesal de los supuestos de despido lesivo de derechos fundamentales.

\section{IV.2.1. La inconstitucionalidad del artículo 34 de la LPCL (STC 01124- 2001-PA/TC)}

El primero de los pronunciamientos pertenece a la sentencia recaída en el expediente 01124-2001-PA/TC, referida al proceso seguido por el Sindicato Unitario de Trabajadores de Telefónica y la Federación de Trabajadores de Telefónica del Perú (FETRATEL) contra Telefónica del Perú S.A.A. y Telefónica Holding S.A, con el objeto de que las últimas se abstengan de amenazar y vulnerar los derechos fundamentales de los trabajadores de afiliados a FETRATEL, en virtud de la aplicación de un Plan de Despido Masivo elaborado por la empresa.

En la citada sentencia, el Tribunal - luego de precisar el contenido de derecho de sindicación y determinar que el criterio de afiliación sindical fue el que se usó para aplicar los despidos masivos_ - analizó los alcances del derecho del trabajo en los términos expuestos supra. Así, el Colegiado determinó que el contenido esencial del derecho al trabajo (consagrado en el artículo 22 de la Constitución) implicaba acceder a un puesto de trabajo y no ser despedido sino por causa justa. En segundo lugar, y más importante, precisó que la remisión a la ley del artículo 27 de la Norma Suprema no constituía un «mandato abierto» al legislador que le permitiría optar, en última instancia, por una legislación que vacíe de contenido al derecho al trabajo.

En efecto, según el Tribunal, como la validez de un desarrollo legal supone el respeto al contenido esencial del derecho objeto de desarrollo ${ }^{40}$, el artículo 34 de la LPCL, al consagrar el despido libre

EL DERECHO AL TRABAJO: EN TRÁNSITO DEL DESPIDO LIBRE AL DERECHO CONSTITUCIONAL GARANTIZADO

\section{THE RIGHT TO}

WORK:TRANSITION FROM FREE DISMISSALTO GUARANTEED CONSTITUTIONAL RIGHT 
indemnizado, vacía de contenido el derecho al trabajo en el extremo que proscribe el despido sin causa justa. Si bien el Protocolo Adicional a la Convención Americana sobre Derechos Humanos en materia de Derechos Económicos, Sociales y Culturales en su artículo 7, apartado «d» permite optar por una reparación indemnizatoria, este instrumento internacional debe entenderse como una norma que enuncia derechos mínimos que los ordenamientos jurídicos internos pueden mejorar con mayores niveles de protección. En otras palabras, bajo ningún caso la incorporación de un tratado de derechos humanos al bloque de constitucionalidad puede significar el menoscabo de los derechos reconocidos en la Constitución, principio que es recogido en el mismo Protocolo, en su artículo 4.

En virtud de lo expuesto, y atendiendo a la imposibilidad de interpretar el artículo 34 de la LPCL de conformidad con la Constitución, el Tribunal inaplicó dicho dispositivo al caso concreto, ordenando la reincorporación a su centro de labores de los trabajadores despedidos y disponiendo que la empresa se abstuviera de seguir con el ejercicio de lo establecido por el artículo 34 respecto de los afiliados a FETRATEL que continuaban laborando. Y no podía ser de otro modo, puesto que la forma de protección del amparo:

[...] no puede ser sino retrotraer el estado de cosas al momento de cometido el acto viciado de inconstitucionalidad, por eso la restitución es una consecuencia consustancial a un acto nulo. La indemnización será una forma de restitución complementaria o sustitutoria si así lo determina libremente el trabajador, pero no la reparación de un acto $a b$ initio inválido por inconstitucional ${ }^{41}$.

La sentencia constituye una respuesta a la absoluta disparidad de la relación empleador/trabajador en la determinación de la culminación de la relación laboral que se evidenció con la forma en que aplicó Telefónica el artículo 34 de la LPCL, desequilibrio que resulta contrario al principio tuitivo de la Constitución. De esta forma, el Tribunal reafirmó que «un Estado constitucional de derecho no tolera ni la arbitrariedad como modo de comportamiento realizado al margen del ordenamiento jurídico, ni tampoco la idea de que, en su seno, existan o puedan existir derechos absolutos» ${ }^{42}$. Si bien esta sentencia se vio matizada por una resolución aclaratoria, los términos antes referidos mantienen su vigor. 


\section{IV.2.1. Nueva tipología de despidos lesivos de derechos constitucionales (STC 00976-2001-PA/TC)}

La segunda sentencia relevante, recaída en el expediente 009762001-PA/TC, amparo interpuesto por Eusebio Llanos Huasco contra Telefónica del Perú S.A., vino a complementar la doctrina desarrollada por el Tribunal en la sentencia del caso FETRATEL. En dicho pronunciamiento, el Tribunal Constitucional no solo reafirmó la inconstitucionalidad del artículo 34 de la LPCL, sino que redefinió la concepción del despido arbitrario, extendiendo erga omnes la garantía de readmisión en el empleo a otros supuestos distintos a los acogidos en la legislación.

Para ello, el Tribunal Constitucional desarrolló una teoría que contempló dos mecanismos de protección frente al despido: los mecanismos sustantivos y los procesales. Los primeros están referidos a la manera en que ha de entenderse la protección adecuada contra el despido del artículo 27 de la Constitución, y abarca mecanismos preventivos - exigencia de causalidad y debido procedimiento previo al cese- - y mecanismos reparadores —compensación económica como sanción frente al despido arbitrario- . Los segundos, por su parte, abarcan mecanismos reparadores - vinculados con acciones indemnizatorias o impugnatorias del despido provenientes de lo dispuesto por la ley- y mecanismos restitutorios - vinculados con acciones de reposición del puesto de trabajo en el amparo, ya que su finalidad es la restitución de las cosas al momento anterior a la violación o amenaza del derecho-.

Así vistas las cosas, el Tribunal consideró que el régimen resarcitorio (indemnización como remedio del despido arbitrario) es compatible con los principios y valores constitucionales cuando el trabajador cobra la indemnización o inicia un proceso para cobrar dicha reparación económica, por ser una decisión libre de este. Opinó, además, que el establecimiento de este régimen no impide que pueda fijarse paralelamente un régimen de protección de eficacia restitutoria (reposición como remedio del despido arbitrario), como sucede en el proceso de amparo, cuyo resultado no puede ser ordenar el pago de una indemnización, sino reponer las cosas al estado anterior a la violación o amenaza de violación de un derecho constitucional.

Tales efectos restitutorios, según el Colegiado, proceden en tres supuestos que han significado una nueva categorización del despido, alejándose de la terminología de la LPCL. Los tres supuestos son:

- Despido incausado, que se caracteriza porque se despide al trabajador de forma verbal o escrita sin expresarle causa alguna derivada de la conducta o la labor. Se decreta la readmisión en el empleo en este supuesto debido a la necesidad de «cautelar 
la vigencia plena del artículo 22 de la Constitución (derecho a trabajo) y demás conexos.

- Despido fraudulento, consistente en el despido con ánimo perverso y auspiciado por el engaño, esto es, de manera contraria a la verdad y a la rectitud de las relaciones laborales, incluso cuando se cumpla con imputar una causa y los cánones procedimentales. Se configura en cualquiera de las siguientes situaciones:

a) Se imputa al trabajador hechos notoriamente inexistentes, falsos e imaginarios.

b) Se atribuye al trabajador una falta no prevista legalmente.

c) Se produce la extinción de la relación laboral con vicio de la voluntad.

d) Se pretende fundamentar falsamente el despido mediante «pruebas fabricadas».

En estas situaciones, según elTribunal, como no existe una causa justa real de despido, ni, al menos, hechos respecto de cuya trascendencia o gravedad corresponda dilucidar al juzgador o por tratarse de hechos no constitutivos de causa justa conforme a la ley, la situación se equipara al despido sin causa ${ }^{43}$.

- Despido nulo, modalidad destinada a proteger derechos constitucionales de especial relevancia para el ordenamiento, como la igualdad, libertad sindical, entre otros. Si bien está recogido en la LPCL (artículo 29), el pronunciamiento del Tribunal amplía la protección contra la discriminación en cualquier supuesto, no solo los enunciados por la ley, además del despido fundado en la condición de portador del VIH del trabajador y por razones de discapacidad.

De este modo, el Tribunal Constitucional concluyó, como en la sentencia del caso FETRATEL, que el régimen de protección adecuada del artículo 27 de la Constitución y que se remitió al legislador no puede entenderse únicamente circunscrito a la LPCL, sino de cara a todo el ordenamiento jurídico. En consecuencia, el régimen de protección contra el despido lesivo de derechos también abarca al proceso de amparo y su efecto restitutorio, en cuanto se esté frente a un despido incausado, fraudulento o nulo. 


\section{IV.2.3. Tutela procesal de los despidos lesivos de derechos fundamentales (STC 00206-2005-PA/TC)}

Finalmente, la sentencia recaída en el expediente 00206-2005-PA/TC, amparo interpuesto por César Baylón Flores contra la E.P.S. EMAPA Huacho S.A., replanteó el esquema procesal de procedencia del despido arbitrario. En efecto, para cuando se emitió la sentencia, la entrada en vigencia del reciente Código Procesal Constitucional había supuesto un cambio en el régimen legal del proceso de amparo, pues estableció la subsidiariedad para la procedencia de las demandas de amparo, cambiando el anterior régimen procesal del amparo que establecía un sistema alternativo.

En virtud de lo expuesto, el Tribunal ha establecido que solo en los casos en que las vías ordinarias no sean idóneas, satisfactorias o eficaces para la cautela del derecho, o por la necesidad de protección urgente, o en situaciones especiales que han de ser analizadas caso por caso por los jueces, será posible acudir a la vía extraordinaria del amparo, correspondiendo al demandante la carga de la prueba para demostrar que el proceso de amparo es la vía idónea y eficaz para restablecer el ejercicio de su derecho constitucional vulnerado, y no el proceso judicial ordinario de que se trate $e^{44}$. Esto como consecuencia de asumir que el primer nivel de protección de los derechos fundamentales les corresponde a los jueces del Poder Judicial a través de los procesos judiciales ordinarios, de conformidad con el artículo 138 de la Constitución.

Efectivamente, manteniendo los criterios jurisprudenciales del expediente 00976-2001-PA/TC (es decir, la categorización en despidos incausados, fraudulentos y nulos), el Supremo Intérprete ha señalado que, si en la vía judicial ordinaria no es posible obtener la reposición o la restitución del derecho vulnerado, el amparo será la vía idónea para obtener la protección adecuada de los trabajadores del régimen laboral privado, incluida la reposición cuando el despido se funde en los supuestos mencionados.

Así, respecto del despido sin imputación de causa, el Tribunal ha indicado que la jurisprudencia es abundante y debe hacerse remisión a ella para delimitar los supuestos en los que el amparo se configura como vía idónea para reponer el derecho vulnerado.

En cuanto al despido fraudulento, según el Tribunal, solo será procedente la vía del amparo cuando el demandante acredite fehaciente e indubitablemente que existió fraude, pues en caso contrario - es decir, cuando haya controversia o duda sobre los hechos-, corresponderá a la vía ordinaria laboral determinar la veracidad o falsedad de ellos ${ }^{45}$.

EL DERECHO AL TRABAJO: EN TRÁNSITO DEL DESPIDO LIBRE AL DERECHO CONSTITUCIONAL GARANTIZADO

THE RIGHTTO WORK:TRANSITION FROM FREE DISMISSAL TO GUARANTEED CONSTITUTIONAL RIGHT 
Tal aseveración, aunque no excluye de tutela a los cuatro casos de despido fraudulento que describe el Tribunal, sí restringe su operatividad al remitir al proceso ordinario aquellos supuestos donde se deba acreditar la presencia del despido fraudulento mediante actividad probatoria dotada de complejidad. Empero, y concordando con Sanguineti, se puede afirmar que en tales situaciones los jueces ordinarios deben actuar como jueces constitucionales, al estar en juego la tutela de derechos fundamentales garantizados por la Norma Suprema, y aplicar por tanto los criterios desarrollados por el Supremo Intérprete de la Constitución, entre ellos la reposición para los despidos fraudulentos ${ }^{46}$.

Por último, en los supuestos de despido nulo, el Tribunal estableció que los despidos originados en la lesión a la libertad sindical y al derecho de sindicación siempre tendrán la tutela urgente del proceso de amparo, aun cuando las vías ordinarias también puedan reparar tales derechos, debido a la importancia de los sindicatos en la sociedad democrática y la obligación estatal de adoptar las medidas necesarias y apropiadas para garantizar a los trabajadores y empleadores el libre ejercicio del derecho de sindicación e impedir todo acto de discriminación tendiente a menoscabar la libertad sindical ${ }^{47}$.

De la misma manera, los despidos originados en la discriminación por razón de sexo, raza, religión, opinión, idioma o de cualquier otra índole tendrán protección a través del amparo, así como los despidos producidos con motivo del embarazo, toda vez que, conforme al artículo 23 de la Constitución, el Estado protege especialmente a la madre, deber que según el Tribunal significa adoptar todas las medidas apropiadas para eliminar la discriminación contra la mujer en la esfera del empleo ${ }^{48}$. De igual forma, el Tribunal determinó que el proceso de amparo es el idóneo frente al despido que se origina en la condición de impedido físico mental, siguiendo los artículos 7 y 23 de la Constitución que les garantiza una protección especial del Estado ${ }^{49}$.

En el año 2012, la Corte Suprema de Justicia acordó en el I Pleno Jurisdiccional Supremo en materia laboral — considerando las tres sentencias emitidas por el TC_- que el juez de trabajo en los procesos laborales ordinarios de la Ley Procesal del Trabajo (ley 26636) y de la Nueva Ley Procesal del Trabajo (ley 29497) está facultado para conocer los procesos de impugnación o nulidad de despido incausado o despido fraudulento, que de ser fundado tengan como consecuencia la reposición del trabajador al centro de trabajo. Los magistrados supremos fundamentaron esta decisión en el rol de guardián de la Constitución 
que corresponde al juez ordinario y en el respeto al derecho a la tutela jurisdiccional efectiva, al trabajo y a la estabilidad laboral, consagrados en la Constitución. Según la Corte Suprema, ello no implica en modo alguno la reducción de las garantías procesales vía proceso constitucional; al contrario, genera la posibilidad de que las partes estructuren mejor su «andamiaje probatorio y argumentativo», en vista de que el proceso ordinario laboral no es privado de estación probatoria, como sucede en el amparo.

\section{IV.2.4. Categorías de trabajadores excluidas por el Tribunal Constitucional de la tutela restitutoria contra el despido}

Mención aparte merece el hecho de que, a la par con esta redefinición jurisdiccional de la estabilidad de salida, el Tribunal Constitucional ha excluido de la tutela restitutoria contra el despido a determinadas categorías de trabajadores: trabajadores de confianza, trabajadores del régimen CAS (Contrato Administrativo de Servicios), trabajadores a tiempo parcial y trabajadores del régimen agrario.

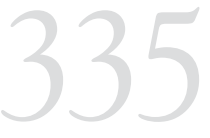

EL DERECHO AL TRABAJO: EN TRÁNSITO DEL DESPIDO LIBRE AL DERECHO CONSTITUCIONAL GARANTIZADO

\section{THE RIGHTTO}

WORK:TRANSITION FROM FREE DISMISSAL TO GUARANTEED CONSTITUTIONAL RIGHT

\section{- Trabajadores de confianza (STC 03501-2006-PA/TC)}

Según el Colegiado, la extinción del vínculo laboral por disposición del empleador para el caso de los trabajadores de confianza no implica su posterior reposición como remedio procesal, como lo manifestó en la sentencia recaída en el expediente 03561-2006-PA/TC, amparo interpuesto por Ricardo David Chávez Caballero contra el Banco Central de Reserva del Perú.

Según el artículo 43 de la LPCL, son trabajadores de confianza aquellos que laboran en contacto personal y directo con el empleador o con el personal de dirección, teniendo acceso a secretos industriales, comerciales o profesionales, y, en general, a información de carácter reservado. Asimismo, son trabajadores de confianza aquellos cuyas opiniones o informes son presentados directamente al personal de dirección, contribuyendo a la formación de las decisiones empresariales. Según el Supremo Intérprete, un trabajador de confianza presenta, además, peculiaridades que lo diferencian de los trabajadores «comunes»: la confianza depositada en él por el empleador; representatividad y responsabilidad en el desempeño de funciones; dirección y dependencia; condición de trabajador de confianza determinada por la naturaleza de la función y no por la persona; entre otras características ${ }^{50}$.

Debido a que la misma relación laboral se fundamenta en la existencia de confianza del empleador hacia el trabajador, este último estará sujeto a la confianza para su estabilidad en el empleo. Por tanto, pese a que la 
causal de «pérdida de la confianza» no está recogida en la ley, el Tribunal ha entendido que esta causal es válida para el término de la relación laboral en trabajadores que han sido de confianza desde el inicio de sus labores. Como se desprende de la naturaleza de la ruptura del vínculo laboral, ante tal supuesto, únicamente procede la indemnización ${ }^{51}$. En casos donde el trabajador haya primero realizado labores ordinarias para luego ser promovido a un cargo de confianza ${ }^{52}$, el Tribunal ha establecido que el trabajador, luego de retirársele la confianza depositada, retornaría a realizar las labores anteriores sin perder el empleo, salvo que se determine que cometió una falta grave que implique su separación de la institución.

La potestad del empleador de culminar el vínculo laboral tampoco puede darse cuando la relación se encuentra suspendida. En efecto, en la sentencia recaída en el expediente 02129-2006-PA/TC, el Colegiado concluyó que, al encontrarse el demandante con licencia por enfermedad, la conclusión de su designación por el empleador vulneró sus derechos a la dignidad y el trabajo, «pues no ha tenido en consideración que, por padecer de una enfermedad, el demandante se encontraba incapacitado temporalmente para prestar sus servicios a la entidad emplazada $»^{53}$.

\section{- Trabajadores del régimen CAS (00002-2010-PI/TC, 2da aclaración)}

Según el Tribunal Constitucional, el Contrato Administrativo de Servicios (CAS) es un régimen laboral especial — diferente y coexistente a los regímenes de los decretos legislativos 276 y 728 - que protege los derechos laborales individuales que la Constitución establece, y que por tanto, es constitucional, debiendo únicamente subsanarse la ausencia de derechos colectivos en el decreto legislativo 1057, norma que consagra el régimen CAS. La temporalidad de este sistema de contratación es acorde con la Norma Suprema, según el Colegiado, limitándose a señalar que es «un régimen laboral especial que respeta los derechos laborales individuales que reconoce la Constitución $»^{54}$.

Asimismo, el Tribunal calificó de «adecuado y compatible con el artículo 27 de la Constitución ${ }^{55}$ el sistema de protección de eficacia resarcitoria contra el despido arbitrario para el régimen CAS recogido en el decreto supremo 075-2008-PCM, que establece la potestad de la entidad pública de resolver unilateralmente el contrato, pudiendo el juez aplicar una penalidad equivalente a dos meses de contraprestaciones dejadas de percibir (artículo 13.3).

51 Fundamento 16.

52 Ello en virtud del artículo 44 de la LPCL: «Todos los trabajadores que directamente o por promoción acceden a puestos de dirección o de confianza se encuentran comprendidos en los alcances del artículo anterior».

53 Fundamento 7.

54 Fundamento 5 de la Aclaratoria 2.

55 Fundamento 6 de la Aclaratoria 2. 
De este modo, este sistema de contratación, que alberga a una gran cantidad de trabajadores estatales, se encuentra impedido de gozar de la tutela restitutoria en supuestos de despido arbitrario, lo que se contradice la jurisprudencia analizada del Tribunal Constitucional respecto del contenido esencial del derecho al trabajo y a la estabilidad laboral, como sucede también en la venia del Colegiado con relación a la temporalidad del CAS.

\section{- Trabajadores a tiempo parcial (STC 00990-2008-PA/TC)}

El Supremo Intérprete de la Constitución se ha pronunciado también excluyendo de tutela restitutoria a los trabajadores a tiempo parcial cuya contratación haya sido concluida unilateralmente por la parte empleadora. En efecto, aplicando una interpretación literal del artículo 22 de la LPCL («Para el despido de un trabajador sujeto a régimen de la actividad privada, que labore cuatro o más horas diarias para un mismo empleador, es indispensable la existencia de causa justa contemplada en la ley y debidamente comprobada»), el Tribunal declaró infundada la demanda presentada por un trabajador que laboraba tres horas diarias y que solicitaba su reposición en su puesto de trabajo.

En vista de esta concepción legalista del Colegiado — que se contradice con los anteriores pronunciamientos del TC-, podemos entender, contrario sensu, que para esta categoría de trabajadores no se requiere causa justa al momento de la culminación unilateral del contrato laboral por parte del patrono, en vista que no se encuentran bajo el amparo del artículo 22 de la LPCL.

\section{IV.2.5. Un último caso: la STC 03052-2009-PA/TC}

Para culminar, cabe señalar que, en el supuesto del cobro de la indemnización por despido arbitrario o de «incentivos» para ello, el trabajador no podría recurrir a la vía constitucional, al haber optado por la vía resarcitoria y no por la reparadora ${ }^{56}$, en tanto que estableció que no se podía validar el acto del despido con el cobro posterior de los beneficios sociales adeudados por el empleador, toda vez que estos le corresponden al trabajador sea cual fuera la causa que motivase su cese laboral ${ }^{57}$. Así, el cobro de tales beneficios correspondería al ejercicio legal de un derecho y no demostraría voluntad alguna del trabajador de dar por terminada la relación laboral. Con esta decisión, que tiene condición de precedente vinculante, modificó justificadamente su jurisprudencia anterior, que había previsto que el cobro de los beneficios sociales implicaba la extinción definitiva del beneficio laboral, dado que esta situación—en palabras del Tribunal—«estaba permitiendo

EL DERECHO AL TRABAJO: EN TRÁNSITO DEL DESPIDO LIBRE AL DERECHO CONSTITUCIONAL GARANTIZADO

THE RIGHTTO WORK:TRANSITION FROM FREE DISMISSALTO GUARANTEED CONSTITUTIONAL RIGHT 
que se vulnere el derecho fundamental al trabajo mediante el despido sin causa ${ }^{58}$. Así se evitaba un accionar doloso por parte del empleador que depositaba los beneficios sociales del trabajador para luego aducir el consentimiento del despido.

Mediante este pronunciamiento, el Colegiado ha impuesto un nuevo supuesto de improcedencia del amparo no previsto en el Código Procesal Constitucional, el mismo que se da cuando el trabajador cobra la indemnización por despido arbitrario ofrecido por el empleador.

\section{CONCLUSIONES FINALES}

De todo lo visto, se puede concluir que el campo del derecho al trabajo resulta especialmente elocuente del proceso de constitucionalización que vive el ordenamiento jurídico laboral desde la restauración democrática a finales del año 2000. La labor del Tribunal Constitucional ha tenido importantes efectos en los ámbitos de la estabilidad de entrada y la de salida, aunque con diferente intensidad.

En el caso de la estabilidad de entrada, la jurisprudencia analizada ha tratado de poner fin a una década en la que la sola utilización de un contrato temporal bastaba para tener una relación legal a plazo fijo, señalando que hay que ver si en los hechos la labor desempeñada concordaba con la contratada, y si había disparidad por tratarse de labores permanentes (fraude) consideraba, de un lado, nula la contratación temporal y, de otro,como despido la terminación del contrato por vencimiento del plazo pactado. Sin embargo, no ha tenido la misma firmeza cuando el objeto mismo del contrato temporal era la realización de labores permanentes, como sucede en el régimen laboral de exportaciones no tradicionales o en el contrato temporal por inicio o incremento de actividades. En el primero de los casos (exportaciones no tradicionales), se ha pronunciado por la validez del régimen legal, contradiciendo el principio de causalidad que él mismo ha reconocido como válido para los primeros casos.

Es por ello que la contratación temporal en el Perú tiene una dimensión inaudita en América Latina (involucra a tres de cada cuatro trabajadores), lo que lleva a que tales trabajadores no tengan protegido su derecho al trabajo, puesto que el mero cumplimiento del plazo previsto en el contrato será una causa válida de extinción, aunque estén desempeñando labores permanentes y les corresponda una extinción debidamente justificada. De este modo, si bien el Tribunal Constitucional ha dado pasos significativos en la lucha contra el fraude 
laboral, queda todavía pendiente la revisión de los contratos temporales usados para labores permanentes.

En el caso de la estabilidad de salida, el proceso de constitucionalización descrito ha tenido una mayor profundidad, puesto que el Tribunal Constitucional ha reformulado la regulación del despido, adecuándola a los cánones constitucionales derivados de la consagración del derecho al trabajo. De este modo, la opción del legislador de un despido libre con la indemnización "como único medio reparatorio» ha sido eliminada de nuestro ordenamiento jurídico, dando lugar a una protección constitucional contra el despido lesivo de derechos fundamentales que abarca una nueva tipología de despido acompañada de medidas restitutorias o reparatorias, según corresponda. Esta corriente jurisprudencial debió haber conducido a una reforma legal de la tipología del despido, lo que no ha ocurrido, por lo que hay que continuar con sus lineamientos. Sí ha tenido impacto en el ámbito del Poder Judicial, donde la Corte Suprema de Justicia ha recogido en el Pleno Jurisdiccional de 2011 que se puede solicitar la reposición en los casos de despido incausado y fraudulento siguiendo el proceso laboral ordinario.

Finalmente, este proceso nos muestra la debilidad de nuestro Estado constitucional, en la medida en que las fuerzas que impulsaron, defendieron y aún defienden la libertad de contratación temporal y de despido han podido neutralizar las iniciativas dirigidas a poner la regulación legal en concordancia con los alcances del derecho constitucional al trabajo establecidos por el Tribunal Constitucional. Tenemos, pues, una importante asignatura pendiente que sigue poniendo a prueba las convicciones constitucionales de nuestros políticos.

EL DERECHO AL TRABAJO: EN TRÁNSITO DEL DESPIDO LIBRE AL DERECHO CONSTITUCIONAL GARANTIZADO

THE RIGHT TO

WORK:TRANSITION FROM FREE DISMISSAL TO GUARANTEED CONSTITUTIONAL RIGHT 